\title{
Is there a subset of patients with preoperatively diagnosed N2 non-small cell lung cancer who might benefit from surgical resection?
}

\author{
Giovanni B. Ratto, MD, ${ }^{\mathrm{a}}$ Roberta Costa, $\mathrm{MD},{ }^{\mathrm{c}}$ Paola Maineri, MD, ${ }^{\mathrm{a}}$ Antonella Alloisio, MD, ${ }^{\mathrm{a}}$ \\ Paolo Bruzzi, MD, ${ }^{\mathrm{b}}$ and Beatrice Dozin, $\mathrm{PhD}^{\mathrm{b}}$
}

Objective: The role of surgery in the treatment of preoperatively diagnosed $\mathrm{N} 2$ non-small cell lung cancer remains controversial. This study sought significant prognostic factors to select candidates for surgery and assess prognosis.

\begin{abstract}
Methods: The study population included 277 patients who underwent primary resection (192) or induction chemotherapy followed by surgery (85) for preoperatively diagnosed, potentially resectable N2 non-small cell lung cancer. N2 descriptors were prospectively recorded. Kaplan-Meier curves were used to evaluate survival, and statistical significance of differences between curves was assessed by log-rank test. Cox regression was used for multivariate analyses.
\end{abstract}

Results: Preoperative significant prognostic factors were number of mediastinal node levels involved $(P<.001)$, symptom severity $(P=.013)$, clinical T $(P=.041)$, and induction chemotherapy $(P=.001)$. Three groups with different prognoses were based on individual prognostic score. The group that did best had a median survival of 29.6 months. Postoperative predictors of survival were pathologic T $(P=.003)$, tumor residue $(P=.034)$, and number of mediastinal nodes involved $(P<.001)$. Of 3 groups with different prognoses, the most favorable had a median survival as long as 42 months.

Conclusion: This study provides a practical tool that uses significant prognostic factors to predict which patients with preoperatively diagnosed N2 non-small cell lung cancer have better prognoses. Because patients with the favorable prognostic factors showed good long-term survival and excellent local disease control, surgery should still play an important role in the multimodality treatment of these patients.

Earn CME credits at

http://cme.ctsnetjournals.org

The role of surgery in the treatment of patients with N2 nonsmall cell lung cancer (NSCLC) has been repeatedly investigated during the last decades. Patients with N2 NSCLC represent an heterogeneous category that includes subsets with different prognoses and treatment options. ${ }^{1}$ Few patients with N2 NSCLC are candidates for curative surgery, and those with preoperative diagnoses appear to have a significantly worse prognosis than those whose $\mathrm{N} 2$ disease is diagnosed intraoperatively. ${ }^{2}$ Controversy persists regarding which patients with preoperatively diagnosed N2 NSCLC are candidates for surgery. ${ }^{2}$ Two recent randomized trials investigated the poten-

\footnotetext{
From the Unit of Thoracic Surgery, Department of Surgical Oncology, ${ }^{\mathrm{a}}$ and the Unit of Clinical Epidemiology, Department of Epidemiology and Prevention, ${ }^{\mathrm{b}}$ National Cancer Research Institute, Genoa, Italy, and the Department of Cardiothoracic Surgery, ${ }^{\mathrm{c}}$ SS Antonio e Biagio e Cesare Arrigo Hospital, Alessandria, Italy.

Received for publication Aug 18, 2008; revisions received Feb 6, 2009; accepted for publication March 8, 2009; available ahead of print June 8, 2009.

Address for reprints: Giovanni B. Ratto, MD, Unit Thoracic Surgery, Department Surgical Oncology, National Cancer Research Institute, Largo Rosanna Benzi 10,

16132 Genoa, Italy (E-mail: giovanni.ratto@ospedalesantacorona.it).

J Thorac Cardiovasc Surg 2009;138:849-58

$0022-5223 / \$ 36.00$

Copyright (C) 2009 by The American Association for Thoracic Surgery

doi:10.1016/j.jtcvs.2009.03.017
}

tial benefits of including surgery in the multimodality treatment of preoperatively diagnosed N2 NSCLC (Radio Therapy Oncology Group [RTOG] 9309³ ; European Organization for Research and Treatment of Cancer [EORTC] $08941^{4}$ ). The first trial (RTOG 9309) addressed this issue in patients with technically resectable N2. Although that trial showed an increased treatment-related mortality in the surgical arm and no significant difference in overall survival between the two arms, a significant improvement in disease-free survival was observed in the surgical arm. The second trial (EORTC 08941) investigated the role of surgery in patients with N2 NSCLC initially judged to be unresectable. Surgery improved neither overall nor disease-free survival, and in the surgical arm, about half of the patients received useless surgery (exploratory thoracotomy or incomplete resection). Furthermore, most patients who did have resection underwent pneumonectomy, suggesting that bronchoplastic and angioplastic techniques were not widely adopted. One might also argue that the disappointing results of the EORTC trial were related to the selection criteria and to the large number of participating centers.

To assess the potential and limits of surgery in preoperatively diagnosed N2 NSCLC, we analyzed 277 consecutive patients who underwent resection by a single surgical team. Preoperative and postoperative prognostic parameters were prospectively collected. The study was designed to record N2 descriptors for every patient and to assess survival according to these prognostic factors. Another aim was to 


\section{Abbreviations and Acronyms \\ $\mathrm{CT}=$ computed tomograpy \\ MLND $=$ mediastinal lymph node dissection \\ NSCLC $=$ non-small cell lung cancer \\ PET = positron emission tomography}

develop two risk scores, one based on preoperative descriptors to avoid selecting patients unsuitable for resection and the other based on postoperative prognostic factors to predict outcome after resection.

\section{MATERIALS AND METHODS}

This study included 277 consecutive patients with preoperatively documented N2 NSCLC who underwent resection and systematic mediastinal lymph node dissection (MLND) between February 1991 and July 2004. All data were prospectively collected. One hundred ninety-two patients were treated with initial surgery and 85 with induction chemotherapy followed by surgery (Figure 1). Before induction chemotherapy became the standard treatment for N2 NSCLC in our institution, surgery was the initial treatment. By 1999, induction chemotherapy became our first option, and only patients who refused induction chemotherapy were treated primarily with surgery. The N2 status was preoperatively determined by computed tomography (CT) scan (mediastinal nodes with the shorter diameter of 10 $\mathrm{mm}$ or more were considered potentially metastatic) and confirmed by cervical mediastinoscopy or left anterior mediastinotomy, depending on the location of enlarged nodes. Every patient with left-sided NSCLC and a positive left anterior mediastinotomy result underwent cervical mediastinoscopy, regardless of the size of paratracheal and pretracheal nodes. Patients with no sign of enlarged mediastinal nodes on CT scan and those with a negative mediastinoscopy result who had restaging to N2 during surgery were not included in the study. Patients with bulky mediastinal nodes (defined as nodes with the shorter diameter larger than $20 \mathrm{~mm}$ ) were not excluded from the study if resection completeness was expected. Both in the primary surgery period and in the induction chemotherapy period, patients with mediastinoscopic evidence of extranodular tumor spread precluding resectability were denied surgery. Six patients who died within 30 days after surgery were included in the analysis.

The study was approved by the ethical committee of the Institute and conducted in accordance with the International Good Clinical Practice Guidelines. All patients were aware of the aims and procedures of the study, and all signed an informed consent for participating in the study before undergoing induction chemotherapy or before surgery if no induction therapy was used.

\section{Inclusion Criteria}

Inclusion criteria were as follows: (1) preoperative histologic diagnosis of N2 NSCLC by either cervical mediastinoscopy or anterior mediastinotomy; (2) feasibility of achieving complete resection; (3) performance status of 0 or 1; (4) compatible cardiorespiratory function; and (5) no N3 disease, distant metastases, malignant pleural effusion, or vena cava syndrome.

\section{Pretreatment Staging}

Patients with N2 NSCLC, who are at high risk, underwent an extensive preoperative staging, including the following: chest roentgenography; $\mathrm{CT}$ of the brain, chest, and upper abdomen; ultrasonography of the upper abdomen when indicated; magnetic resonance imaging of the brain when indicated on the basis of CT scan findings, bone scan; from 2002 on, positron emission tomography (PET) scan (in these cases, bone scan was avoided); bronchoscopy; and mediastinoscopy. After the introduction of PET scanning, patients with

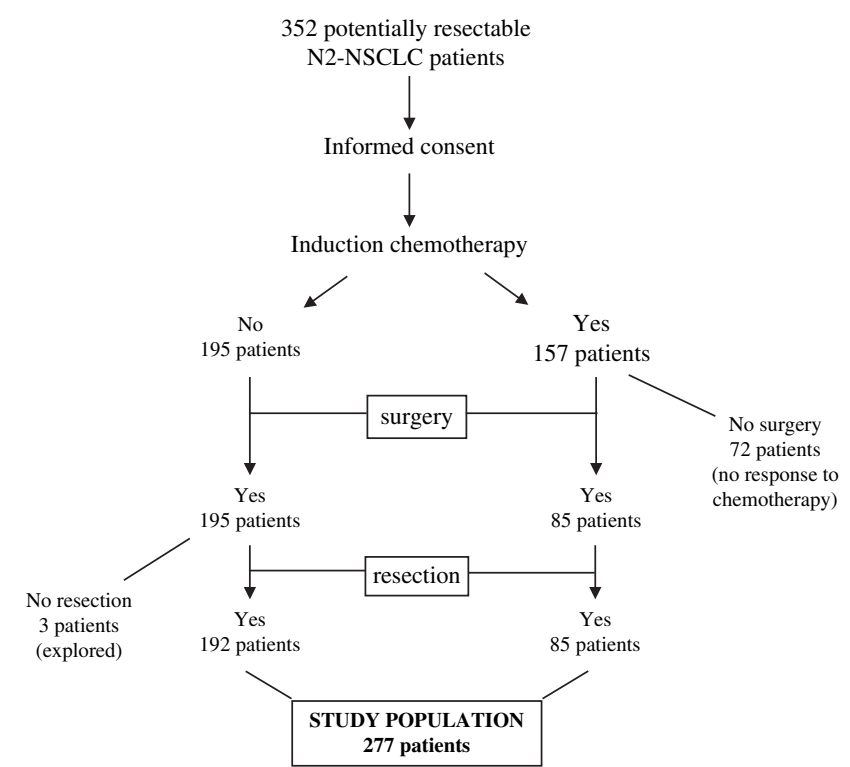

FIGURE 1. Algorithm for selection of study patient population. NSCLC, Non-small cell lung cancer.

positive mediastinal nodes on PET scan (regardless of the diameter of mediastinal nodes on CT scan) and those with enlarged mediastinal nodes on CT scan (regardless of PET scan findings) underwent mediastinoscopy.

\section{Preoperative Functional Evaluation}

Pulmonary functional evaluation included blood gas analysis, spirometry, and quantitative lung ventilation/perfusion scans (except for patients with a normal results of spirometry). Determination of the maximum oxygen consumption during exercise was used when predicted postoperative values of either forced expiratory volume in 1 second or diffusing capacity for carbon monoxide was lower than $40 \%$ predicted. Patients were judged suitable for resection when maximum oxygen consumption was greater than $15 \mathrm{~mL} / \mathrm{kg} / \mathrm{min}$. Cardiac risk was assessed by stress echocardiography in patients with a history of heart symptoms or abnormal electrocardiogram.

\section{Treatment Plan}

A platinum-based $\left(80 \mathrm{mg} / \mathrm{m}^{2}\right)$ induction regimen combined with at least one other drug (gemcitabine, paclitaxel, or vinorelbine) was used. The treatment cycle was repeated two more times at 3-week intervals in patients who had sufficient recovery from toxic effects of the previous cycle. Because all patients had disease that was initially judged resectable, neoadjuvant radiation therapy was never used. After induction chemotherapy, all patients again underwent CT scans of the brain, chest, and upper abdomen, along with bronchoscopy and functional evaluation. Repeated mediastinoscopy or endobronchial ultrasonography was not included in this evaluation. Starting from 2002, all patients underwent a PET scan 3 to 4 weeks after the completion of induction chemotherapy to evaluate the metabolic response to the induction treatment (standardized uptake values). Patients showing no response to the induction treatment or showing severe chemotherapy toxicity did not undergo surgery and were excluded from the study. Adjuvant radiation therapy to the mediastinum (45-50 Gy) was given to most patients. Patients with incomplete resections ( $\mathrm{R} 1$ or $\mathrm{R} 2$ ) received further radiotherapy to the residual disease (60 Gy).

\section{Surgery}

All operations were performed according to the same oncologic and technical principles. Tumors adhering to the pericardium, thoracic wall, diaphragm, atrium, or great vessels were approached with en bloc removal of lung and 
TABLE 1. Univariate and multivariate analyses: Survival according to preoperative factors

\begin{tabular}{|c|c|c|c|c|c|c|c|c|c|}
\hline \multirow[b]{2}{*}{ Factor } & \multicolumn{2}{|c|}{ Patients } & \multicolumn{2}{|c|}{ Deaths } & \multicolumn{2}{|l|}{ Univariate } & \multicolumn{3}{|c|}{ Multivariate } \\
\hline & No. & $\%$ & No. & $\%$ & Median survival (mo) & $P$ value* & HR & $95 \% \mathrm{CI}$ & $\boldsymbol{P}$ value $\dagger$ \\
\hline Sex & & & & & & .8525 & RFM & & .821 \\
\hline Male & 229 & $82.7 \%$ & 157 & $63.6 \%$ & 20.5 & & - & - & \\
\hline Female & 48 & $17.3 \%$ & 28 & $58.3 \%$ & 19.9 & & - & - & \\
\hline Age (y) & & & & & & .3328 & RFM & & .718 \\
\hline$<60$ & 74 & $26.7 \%$ & 55 & $74.3 \%$ & 17.0 & & - & - & \\
\hline $60-65$ & 68 & $24.5 \%$ & 41 & $60.3 \%$ & 22.7 & & - & - & \\
\hline $65-70$ & 63 & $22.7 \%$ & 46 & $73.0 \%$ & 19.9 & & - & - & \\
\hline$>70$ & 72 & $26.0 \%$ & 43 & $59.7 \%$ & 20.0 & & - & - & \\
\hline $\begin{array}{l}\text { Performance status } \\
\text { (Eastern Cooperative } \\
\text { Oncology Group) }\end{array}$ & & & & & & .2069 & RFM & & .074 \\
\hline 0 & 182 & $65.7 \%$ & 121 & $66.5 \%$ & 21.2 & & - & - & \\
\hline$>0$ & 95 & $34.3 \%$ & 64 & $67.4 \%$ & 18.5 & & - & - & \\
\hline Symptoms $\ddagger$ & & & & & & .0129 & & & .013 \\
\hline None (reference) & 63 & $22.7 \%$ & 39 & $61.9 \%$ & 23.6 & & 1 & - & \\
\hline Mild & 65 & $23.5 \%$ & 41 & $63.1 \%$ & 21.2 & & 1.311 & $0.842-2.042$ & \\
\hline Moderate & 83 & $30.0 \%$ & 52 & $62.7 \%$ & 20.6 & & 1.116 & $0.727-1.712$ & \\
\hline Severe & 66 & $23.8 \%$ & 53 & $80.3 \%$ & 12.8 & & 1.987 & $1.243-2.896$ & \\
\hline Clinical T status & & & & & & .0688 & TT & - & .041 \\
\hline $\mathrm{T} 1$ & 34 & $12.3 \%$ & 19 & $55.9 \%$ & 23.3 & & - & - & \\
\hline $\mathrm{T} 2$ & 159 & $57.4 \%$ & 101 & $63.5 \%$ & 22.0 & & - & - & \\
\hline $\mathrm{T} 3$ & 67 & $24.2 \%$ & 51 & $76.1 \%$ & 14.6 & & - & - & \\
\hline $\mathrm{T} 4$ & 17 & $6.1 \%$ & 14 & $82.3 \%$ & 18.0 & & 1.236 & $1.011-1.510$ & \\
\hline $\begin{array}{r}\text { Lymph node levels } \\
\text { involved (no.) }\end{array}$ & & & & & & $<.0001$ & & & $<.001$ \\
\hline 1 (reference) & 184 & $66.4 \%$ & 110 & $59.8 \%$ & 22.7 & & 1 & - & \\
\hline 2 & 70 & $25.3 \%$ & 56 & $80.0 \%$ & 16.8 & & 1.744 & $1.256-2.422$ & \\
\hline$>2$ & 23 & $8.3 \%$ & 19 & $82.6 \%$ & 11.1 & & 3.109 & $1.869-5.173$ & \\
\hline Bulky tumor $\S$ & & & & & & .7276 & RFM & & .636 \\
\hline No & 247 & $89.2 \%$ & 163 & $66.0 \%$ & 20.8 & & - & - & \\
\hline Yes & 30 & $10.8 \%$ & 22 & $73.3 \%$ & 17.5 & & - & - & \\
\hline Induction chemotherapy & & & & & & .0012 & & & \\
\hline No (reference) & 192 & $69.3 \%$ & 143 & $74.5 \%$ & 18.7 & & 1 & - & \\
\hline Yes & 85 & $30.7 \%$ & 42 & $49.4 \%$ & 27.1 & & 0.543 & $0.380-0.778$ & .001 \\
\hline Site of neoplasia & & & & & & .1414 & RFM & & .490 \\
\hline Right & 159 & 118 & 111 & 74 & 18.7 & & - & - & \\
\hline Left & $57.4 \%$ & $42.6 \%$ & $60.0 \%$ & $40.0 \%$ & 21.9 & & - & - & \\
\hline
\end{tabular}

In multivariate Cox model, all variables were initially included in the model. Variables not significantly associated with overall survival $(P>.05)$ were removed from the model by means of a step-down procedure. $H R$, Hazard ratio; $C I$, confidence interval; $R F M$, removed from final model; $T T$, test for trend. $* B y$ log-rank test. $\dagger B y$ Cox regression $\left(\chi^{2}\right)$. $\ddagger$ Symptoms were graded as follows: mild, cough, asthenia; moderate, exerting dyspnea, fever, blood-tinged or blood-streaked sputum, weight loss less than $5 \%$ of body weight; severe, hemoptysis (defined as whole blood sputum), pain, dyspnea while resting, weight loss more than $5 \%$ of body weight. $§$ Bulky mediastinal nodes were defined as nodes with the shorter diameter larger than $20 \mathrm{~mm}$.

involved structures. Wedge resections were never performed. Sleeve resections were preferred to pneumonectomy whenever the completeness of resection was not jeopardized. Complete MLND was performed in all cases as previously described. ${ }^{5,6}$ All nodes encountered were removed from the Naruke map areas $11,10,9,8,7,4,3$, and 2 for tumors of the right side and from the areas $11,10,9,8,7,6$, and 5 for those of the left side. Patients were considered to have complete resection (R0) whenever no gross residual tumor was left, the margins of the resection were microscopically free of cancer, and no metastasis was found in the highest lymph node dissected. ${ }^{7} \mathrm{R} 1$ and $\mathrm{R} 2$ resections indicate microscopic and macroscopic residual tumor, respectively.

\section{Follow-up}

Follow-up included physical examination, routine blood tests, and chest radiography every 3 months for the first 2 years, every 6 months during the third year, and once a year thereafter. For most patients, CT scans of the chest and upper abdomen were done at 12 and 24 postoperative months, unless a relapse was suspected before.

\section{Statistical Analysis}

All eligible patients who underwent resection during the study period were included in the analysis. The primary end point was overall survival computed from the date of surgery to the date of last contact or the date of death from any cause. Kaplan-Meier curves were used to evaluate survivals of each group, and the statistical significance of differences between curves was assessed with the log-rank test. All variables used as potential risk factors are listed in Tables 1 and 2. Cox regression was used for multivariate analyses to assess the independent role of each prognostic factor 
TABLE 2. Univariate and multivariate analyses: Survival according to postoperative factors

\begin{tabular}{|c|c|c|c|c|c|c|c|c|c|}
\hline \multirow[b]{2}{*}{ Factor } & \multicolumn{2}{|c|}{ Patients } & \multicolumn{2}{|c|}{ Events } & \multicolumn{2}{|l|}{ Univariate } & \multicolumn{3}{|c|}{ Multivariate } \\
\hline & No. & $\%$ & No. & $\%$ & Median survival (mo) & $P$ value* & HR & $95 \% \mathrm{CI}$ & $P$ value $\dagger$ \\
\hline Surgery & & & & & & .0023 & RFM & & .098 \\
\hline Pneumonectomy & 69 & $24.9 \%$ & 52 & $75.4 \%$ & 13.5 & & - & - & \\
\hline $\begin{array}{l}\text { Lobectomy or } \\
\text { bilobectomy }\end{array}$ & 208 & $75.1 \%$ & 133 & $63.9 \%$ & 22 & & - & - & \\
\hline Histologic type & & & & & & .0103 & RFM & & .102 \\
\hline $\begin{array}{l}\text { Squamous } \\
\text { carcinoma }\end{array}$ & 139 & $50.2 \%$ & 89 & $64.0 \%$ & 22 & & - & - & \\
\hline Adenocarcinoma & 115 & $41.5 \%$ & 86 & $74.8 \%$ & 17.8 & & - & - & \\
\hline Other & 23 & $8.3 \%$ & 10 & $43.5 \%$ & 42.4 & & & & \\
\hline Grading category $\ddagger$ & & & & & & .2557 & RFM & & .735 \\
\hline G0 & 10 & $3.6 \%$ & 4 & $40.0 \%$ & 70.2 & & - & - & \\
\hline G1-G2 & 155 & $56.0 \%$ & 110 & $71.0 \%$ & 20 & & - & - & \\
\hline G3-G4 & 112 & $40.4 \%$ & 71 & $63.4 \%$ & 19.7 & & - & - & \\
\hline pT & & & & & & $<.0001$ & & & .003 \\
\hline T0 (reference) & 10 & $3.6 \%$ & 4 & $40.0 \%$ & 70.2 & & 1 & & \\
\hline $\mathrm{T} 1$ & 46 & $16.6 \%$ & 23 & $50.0 \%$ & 25.4 & & 1.085 & $0.352-3.349$ & \\
\hline $\mathrm{T} 2$ & 124 & $44.8 \%$ & 77 & $62.1 \%$ & 23.6 & & 1.198 & $0.404-3.552$ & \\
\hline $\mathrm{T} 3$ & 54 & $19.5 \%$ & 40 & $74.1 \%$ & 14.5 & & 1.678 & $0.551-5.113$ & \\
\hline $\mathrm{T} 4$ & 43 & $15.5 \%$ & 41 & $95.4 \%$ & 12.4 & & 2.564 & $0.854-7.699$ & \\
\hline Tumor size $(\mathrm{cm})$ & & & & & & & & & \\
\hline 0 & 10 & $3.6 \%$ & 4 & $40.0 \%$ & 70.2 & .9404 & NI & & \\
\hline$>0,<2.5$ & 52 & $18.8 \%$ & 33 & $63.5 \%$ & 24.6 & & - & - & \\
\hline $2.5-3.5$ & 62 & $22.4 \%$ & 40 & $64.5 \%$ & 19.9 & & - & - & \\
\hline $3.5-5.0$ & 87 & $31.4 \%$ & 64 & $73.5 \%$ & 19.8 & & - & - & \\
\hline$>5.0$ & 66 & $23.8 \%$ & 44 & $66.6 \%$ & 18.6 & & - & - & \\
\hline $\mathrm{pN}$ & & & & & & .0006 & NI & & \\
\hline No & 25 & $9.0 \%$ & 6 & $24.0 \%$ & 75.1 & & - & - & \\
\hline N1 & 5 & $1.8 \%$ & 0 & $0 \%$ & - & & - & - & \\
\hline $\mathrm{N} 2$ & 247 & $89.2 \%$ & 179 & $72.5 \%$ & 18.9 & & - & - & \\
\hline $\begin{array}{l}\text { Lymph nodes involved } \\
\text { (no.) }\end{array}$ & & & & & & $<.0001$ & & & $<.001$ \\
\hline 0 (reference) & 30 & $10.8 \%$ & 6 & $20.0 \%$ & 75.1 & & 1 & & \\
\hline $1-3$ & 105 & $37.9 \%$ & 60 & $57.1 \%$ & 24.6 & & 2.11 & $0.856-5.202$ & \\
\hline $4-9$ & 93 & $33.6 \%$ & 74 & $79.6 \%$ & 16.6 & & 3.446 & $1.405-8.443$ & \\
\hline$>9$ & 49 & $17.7 \%$ & 45 & $91.8 \%$ & 12.7 & & 4.83 & $1.892-12.333$ & \\
\hline $\begin{array}{l}\text { Lymph node levels } \\
\text { involved (no.) }\end{array}$ & & & & & & $<.0001$ & RFM & & .107 \\
\hline 0 & 30 & $10.8 \%$ & 6 & $20.0 \%$ & 75.1 & & - & - & \\
\hline 1 & 121 & $43.7 \%$ & 79 & $65.3 \%$ & 23.6 & & - & - & \\
\hline 2 & 76 & $27.4 \%$ & 57 & $75.0 \%$ & 16.8 & & - & - & \\
\hline$>2$ & 50 & $18.1 \%$ & 43 & $86.0 \%$ & 12.7 & & - & - & \\
\hline Resection completeness & & & & & & $<.0001$ & & & .034 \\
\hline R0 (reference) & 219 & $79.1 \%$ & 132 & $60.3 \%$ & 23.6 & & 1 & & \\
\hline $\mathrm{R} 1$ & 44 & $15.9 \%$ & 39 & $88.6 \%$ & 12.4 & & 1.487 & $0.998-2.214$ & \\
\hline $\mathrm{R} 2$ & 14 & $5.0 \%$ & 14 & $100 \%$ & 8.6 & & 1.954 & $1.069-3.574$ & \\
\hline Skip metastasis $\S$ & & & & & & .5203 & RFM & & .851 \\
\hline No & 215 & $77.6 \%$ & 142 & $66.0 \%$ & 20.6 & & - & - & \\
\hline Yes & 62 & $22.4 \%$ & 43 & $69.4 \%$ & 18.7 & & - & - & \\
\hline Extranodal spread $\S$ & & & & & & .0001 & RFM & & .341 \\
\hline No & 219 & $79.1 \%$ & 137 & $62.6 \%$ & 22.7 & & - & - & \\
\hline Yes & 58 & $20.9 \%$ & 48 & $82.8 \%$ & 13.0 & & - & - & \\
\hline Bulky mediastinal nodes $\S$ & & & & & & .0082 & RFM & & .404 \\
\hline No & 240 & $86.6 \%$ & 153 & $63.7 \%$ & 21.2 & & - & - & \\
\hline Yes & 37 & $13.4 \%$ & 32 & $86.5 \%$ & 12.8 & & - & - & \\
\hline
\end{tabular}


TABLE 2. Continued

\begin{tabular}{|c|c|c|c|c|c|c|c|c|c|}
\hline \multirow[b]{2}{*}{ Factor } & \multicolumn{2}{|c|}{ Patients } & \multicolumn{2}{|c|}{ Events } & \multicolumn{2}{|l|}{ Univariate } & \multicolumn{3}{|c|}{ Multivariate } \\
\hline & No. & $\%$ & No. & $\%$ & Median survival (mo) & $P$ value* & HR & $\mathbf{9 5} \% \mathrm{CI}$ & $P$ value $\dagger$ \\
\hline \multicolumn{10}{|l|}{ Adjuvant therapy } \\
\hline None & 82 & $29.6 \%$ & 47 & $57.3 \%$ & 19.9 & .9082 & RFM & & .166 \\
\hline Chemotherapy & 15 & $5.4 \%$ & 12 & $80.0 \%$ & 17.8 & & - & - & \\
\hline Radiotherapy & 105 & $39.4 \%$ & 74 & $67.9 \%$ & 21.8 & & - & - & \\
\hline Chemoradiotherapy & 71 & $25.6 \%$ & 52 & $73.2 \%$ & 16.8 & & - & - & \\
\hline
\end{tabular}

In multivariate Cox model, all variables were initially included in the model. Variables not significantly associated with overall survival $(P>.05)$ were removed from the model by means of a step-down procedure. $H R$, Hazard ratio; $C I$, confidence interval; $R F M$, removed from final model; $N I$, not included in equation for computational reasons. $*$ By log-rank test. $\dagger$ By Cox regression $\left(\chi^{2}\right)$. $\Varangle$ Grade was assessed in a double-blinded manner by two experienced pathologists according to the classification of the World Health Organization. $\S$ Skip metastasis was defined as metastasis to mediastinal nodes without involvement of bronchopulmonary nodes; extranodal spread was defined as proliferating tumor cells present in perinodal tissue; bulky mediastinal nodes were defined as nodes with the shorter diameter larger than $20 \mathrm{~mm}$.

while adjusting for the effects of other factors. Multivariate analyses started from the full model, with all covariates included, unless indicated otherwise. Factors not significantly $(P>.05)$ associated with survival were then removed from the model by means of a step-down procedure that was based on the likelihood ratio test. Hazard ratios of the variables included in the final model were obtained by exponentiating the coefficients estimated by the Cox model. The prognostic profile of each patient was then used to compute an individual risk score on the basis of the coefficients of the prognostic variables included in the final model. Individual risk scores were computed by multiplying the hazard ratios associated with the prognostic profile of each individual, as estimated in Cox regression analyses. Three groups of risk score-low, medium and high — were established on the basis of the tertiles of individual patient scores. Details on how to compute individual risk scores are shown in Figure 2. Survivals of the three groups were then evaluated. Two different sets of models were fitted. The first model included only preoperative information, to predict the prognoses of patients with N2 NSCLC who were candidates for resection. The second included both preoperative and surgical information, to assess the individual prognosis. Statistical analyses was carried out with the SPSS package (version 11 for Windows; SPSS, Inc, Chicago, Ill).

\section{RESULTS}

From 1991 to 2004, a total of 352 patients with N2 NSCLC were selected as having technically resectable disease (Figure 1). Of these, $157(157 / 352,44.6 \%)$ received induction chemotherapy and $195(195 / 352,55.4 \%)$ did not. Among the 157 patients who underwent induction chemotherapy, $72(72 / 157,45.7 \%)$ did not progress to surgery because of deterioration in overall health status, complications after chemotherapy, or disease progression. The other 85 patients $(85 / 157,54.3 \%)$ with responses to the treatment underwent resection. Among the 195 patients who went straight to surgery, $3(3 / 195,1.5 .0 \%)$ underwent exploration only and $192(192 / 195,98.5 \%)$ underwent resection. The 3 patients with exploration only were excluded from the analysis, because only patients with resection were included in the study population. The rate of complete resection (R0) was $79 \%$ (219/277 patients). An incomplete resection was performed in 58 cases: R1 in 44 patients $(44 / 277,15.9 \%)$ and R2 in 14 patients $(14 / 277,5.1 \%)$. Details on patients receiving induction chemotherapy but not proceeding to surgery have not been provided, because assessing the role of induction chemotherapy was out of the scope of this study.
The median observation time from surgery to death or censoring was 16.8 months (range 16 days-116 months). Ninety-two patients $(92 / 277,33.2 \%)$ were alive at the end of the follow-up period, with a median follow-up of 30 months (range 7.9-116 months). Eighty-three of these patients $(83 / 277,30.0 \%)$ were free from relapse. Overall, 185 patients $(185 / 277,66.8 \%)$ died during follow-up. One hundred fifty-five of these patients died from tumor relapse. Relapse sites were local $(44 / 277,15.9 \%)$, contralateral lung $(32 / 277,11.6 \%)$, adrenal gland $(5 / 277,1.8 \%)$, brain $(29 /$ $277,10.5 \%)$, skeleton $(8 / 277,2.9 \%)$, and liver $(1 / 277$, $0.4 \%)$. Recurrences were local and systemic in $8.3 \%(23 /$ 277 ) and systemic multiple in $7.9 \%(22 / 277$,$) . Thirty pa-$ tients died without a diagnosis of tumor relapse. Cumulative overall survivals at 1,3 , and 5 years in the entire group of patients were $72.6 \%, 37.5 \%$, and $21.3 \%$, respectively. Median overall survival was 16.8 months.

Patient clinical profiles are shown in Table 1. In univariate analysis, the preoperative factors significantly associated with survival were the severity of symptoms $(P=.0129)$, the number of lymph node levels involved $(P<.0001)$, and induction chemotherapy $(P=.0012)$. An association of borderline significance $(P=.0688)$ was observed between $\mathrm{T}$ status and survival. Particularly poor survivals were observed for patients with severe symptoms (median survival 12.8 months), for patients with T3 (median survival 14,6 months), and for patients with involvement of more than 2 lymph node levels (median survival 11.1 months). In multivariate analysis, the following factors were found to be significant independent predictors of survival: number of involved nodal stations $(P<.001)$, severity of symptoms $(P=.013)$, preoperative T status $(P$ $=.041)$, and induction chemotherapy $(P=.001)$. The survivals of the three risk group of patients, calculated as described here, are shown in Figure 3. It is interesting to note that the difference between the best prognosis group and the intermediate prognosis group started to become noticeable only 2 years after surgery. Overall survivals in the best prognosis group were $40 \%$ and $32 \%$ at 5 and 8 years, respectively. Conversely, overall survival in the worst 
Preoperative individual score $=\left(\begin{array}{l}1.00 \text { if symptoms }=\text { null } \\ 1.16 \text { if symptoms }=\text { mild } \\ 1.30 \text { if symptoms }=\text { moderate } \\ 1.80 \text { if symptoms }=\text { severe }\end{array}\right) \times\left(\begin{array}{l}1.00 \text { if number of levels }=1 \\ 1.67 \text { if number of levels }=2 \\ 3.26 \text { if number of levels }>2\end{array}\right] \times\left(\begin{array}{l}1.00 \text { if clinical } \mathrm{T}=1 \\ 1.03 \text { if clinical } \mathrm{T}=2 \\ 1.58 \text { if clinical } \mathrm{T}=3 \\ 1.78 \text { if clinical } \mathrm{T}=4\end{array}\right]$

Score $\leq 1.34=$ low risk

Score $>1.34-\leq 2.07=$ medium risk

Score $>2.07=$ high risk

Postoperative individual score $=\left(\begin{array}{l}1.00 \text { if tumor residue }=\text { null } \\ 1.48 \text { if tumor residue }=\text { minimal } \\ 2.17 \text { if tumor residue }=\text { extended }\end{array}\right) \times\left(\begin{array}{l}1.00 \text { if number of nodes }=0 \\ 2.72 \text { if number of nodes }=1 \text { to } 3 \\ 4.63 \text { if number of nodes }=4 \text { to } 9 \\ 6.16 \text { if number of nodes }>9\end{array}\right] \times\left(\begin{array}{l}1.00 \text { if pathological } \mathrm{T}=0 \\ 1.05 \text { if pathological } \mathrm{T}=1 \\ 1.07 \text { if pathological } \mathrm{T}=2 \\ 1.61 \text { if pathological } \mathrm{T}=3 \\ 2.41 \text { if pathological } \mathrm{T}=4\end{array}\right)$

Score $\leq 2.92=$ low risk

Score $>2.92-\leq 6.56=$ medium risk

Score $>6.56=$ high risk

FIGURE 2. Equation for individual risk score evaluation. Hazard ratios reported for each prognostic factor are derived from multivariate Cox regression. Patient individual risk score is determined by multiplying hazard ratios corresponding to diagnosis. Threshold values of risk scores are based on tertiles of individual patient scores.

prognosis group was very poor $(22 \%$ at 2 years and $<10 \%$ at 5 years).

The pathologic and surgical descriptors are listed in Table 2. At surgery, 30 patients $(30 / 277,10.8 \%)$ were found to have N0 disease at the level of the mediastinum. All these patients had received induction chemotherapy. Among them, 25 had disease classified as pN0, whereas the remaining 5 had a classification of $\mathrm{pN} 1$. In univariate analysis, the factors significantly associated with survival were as follows: type of surgery $(P=.002)$, histologic type $(P=.0103)$, pathologic $\mathrm{T}$ status $(P<.0001)$, N status $(P=.0006)$, number of lymph nodes involved $(P<.0001)$, number of lymph node stations involved $(P<.0001)$, incomplete resection $(\mathrm{R} 1-\mathrm{R} 2, P<$ $.0001)$, extranodal metastases $(P=.0001)$, and bulky N2 $(P=.0082)$. A multivariate Cox regression was then performed. It included all the postoperative factors except $\mathrm{N}$ status (TNM classification system), tumor diameter, and histologic type. The first two factors were omitted because of collinearity with the number of metastatic lymph nodes and with the pathologic $\mathrm{T}$ status, respectively. Histologic type was omitted because no difference in survival was seen between squamous carcinoma and adenocarcinoma, whereas the number of patients with other tumors was very small $(n=23)$, precluding convergence of the statistical models. The significant predictors of survival were as follows: pathologic T status $(P=.003)$, incomplete resection (R1-R2, $P=.034)$, and number of lymph nodes involved $(P<.001)$. Again, an individual prognostic score was computed, and the survivals of the three groups created are shown in Figure 4.

A single multivariate analysis combining all the significant preoperative and postoperative prognostic factors showed that only the three postoperative factors could be maintained in the final analysis: pathologic T status $(P=$ $.002)$, incomplete resection (R1-R2, $P=.020)$, and number of lymph nodes involved $(P<.001)$. Conversely, all four preoperative factors were no longer significantly associated with survival and were removed from the model. Thus the three significant postoperative factors appear to supplant completely the prognostic role of the preoperative factors. The 5-year overall survivals were $47 \%, 16 \%$, and $5 \%$ in the best, the intermediate, and the worst prognosis groups, respectively.

\section{DISCUSSION}

Although it has been repeatedly stressed that preoperatively demonstrated $\mathrm{N} 2$ disease is one of the most unfavorable prognostic factors in resected NSCLC, ${ }^{1,7-12}$ controversy still persists as to which factors have greater influence on prognosis and which treatment option offers the best long-term survival. This study attempted to answer these questions, although the selection criteria used here were rather stringent and allowed us to obtain results that could have been worse if less restrictive settings had been applied.

Searching for significant prognostic factors in patients with N2 disease, Martini and colleagues ${ }^{13}$ and Goldstraw and associates ${ }^{6}$ found that patients with the involvement of a single nodal station did significantly better than did patients with more stations involved. Suzuki and coworkers ${ }^{14}$ studied 16 clinical and pathologic factors in 95 patients with N2 NSCLC who underwent resection. Four negative prognostic factors were identified: clinical N2, incomplete resection, large tumor size, and multiple station N2 metastases. Unfortunately, in that study the N2 status was assessed 


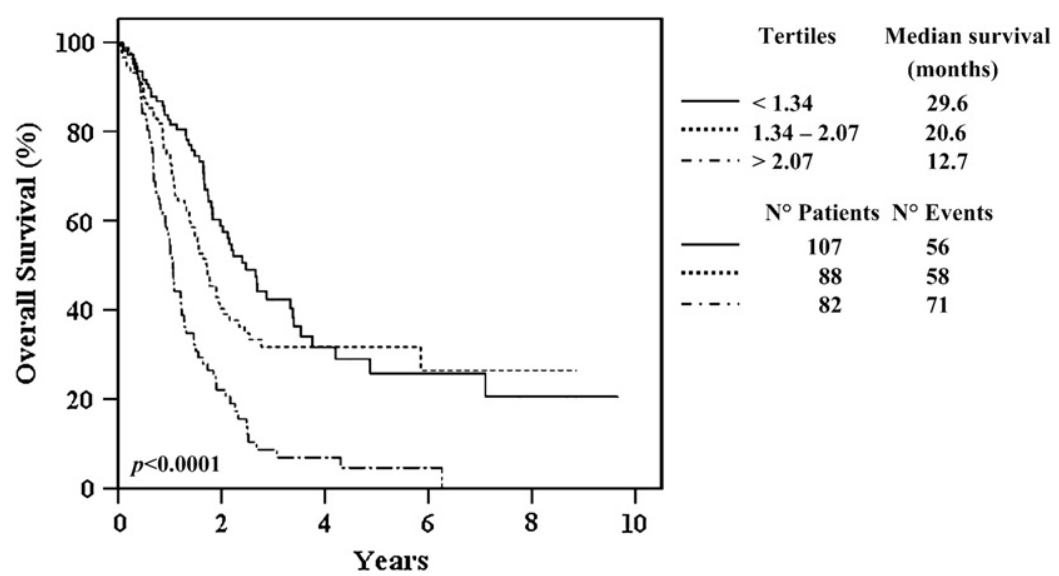

FIGURE 3. Overall survivals of three patient groups created on basis of tertiles of individual preoperative prognostic scores. Scores were derived from hazard ratio coefficients estimated by multivariate analysis.

only on CT scan imaging, and no mediastinoscopic demonstration was provided. Andre and associates ${ }^{1}$ investigated 702 consecutive patients who underwent surgical resection at six French institutions. They found four negative prognostic factors: clinical N2, involvement of multiple lymph node stations, pT3 or pT4, and lack of preoperative chemotherapy. Ruckdeshel and coworkers ${ }^{15}$ and Vansteenkiste and colleagues ${ }^{16}$ reported that patients with a limited number of lymph node stations involved at mediastinoscopy could be considered candidates for surgical resection. Similarly, Japanese researchers reported a better 5-year survival for patients with a limited number of N2 nodes involved. ${ }^{13,17,18}$ When interpreting the influences of all these prognostic factors on survival, we should consider that their values are related to a number a variables, including the extent of MLND and the criteria used for defining potentially resectable N2 disease.

The need for routine MLND, remains controversial in not only the treatment but also the staging of NSCLC. In a nonrandomized study, Keller and colleagues ${ }^{19}$ reported that systematic sampling is as useful as MLND in staging of NSCLC, whereas MLND identifies significantly more stations of involved N2 nodes. In this study, we assumed that MLND would be essential for assessment of the prognostic significance of the N2 status predictors. MLND has also been associated with improved survival in right-sided but not left-sided NSCLC. ${ }^{19}$ Differences in lymphatic drainage patterns and the limited surgical access to paratracheal nodes in the left side of the chest are possible explanations. In this study, in which the mediastinum was extensively investigated before surgery, there was no significant difference in survival between right-sided and leftsided tumors.

Although the criteria for defining potentially resectable N2 disease remain highly subjective, we have attempted to standardize the selection of patients with N2 NSCLC by using (1) uniform staging and inclusion criteria, except for the introduction of PET scan during the last years; (2) routine mediastinoscopy; and (3) mediastinoscopic detection of unsuspected paratracheal metastatic nodes in patients with

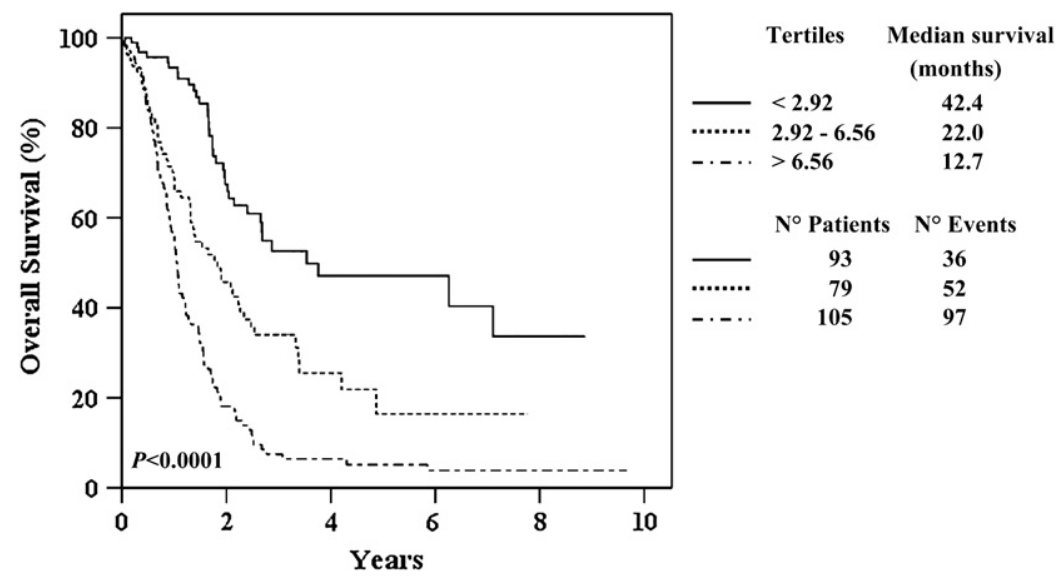

FIGURE 4. Overall survivals of three patient groups created on basis of tertiles of individual postoperative prognostic scores. Scores were derived from hazard ratio coefficients estimated by multivariate analysis. 
left-sided NSCLC and preaortic or subaortic nodes involved. With regard to mediastinal node staging, the introduction of PET scan did not significantly change the diagnostic approach throughout the study; only 2 patients with mediastinal nodes less than $10 \mathrm{~mm}$ had a positive PET scan of the mediastinum.

This study shows that the group of patients with preoperatively diagnosed N2 NSCLC is indeed heterogeneous, and that three subgroups of patients with different prognoses can be identified according to significant prognostic factors (severity of symptoms, clinical T status, number of mediastinal nodal levels involved, and induction chemotherapy). Interestingly, in a group with otherwise poor prognosis, a subset of patients with a median survival of 29.6 months could be distinguished preoperatively. When postoperative significant factors (pathologic $\mathrm{T}$ status, number of lymph nodes involved, and complete surgical resection) are considered, the clinical N2 NSCLC group can be divided into three other subsets with different prognoses, among which the most favorable showed a median survival as long as 42 months.

The multivariate analyses also indicated that bulky N2 and extracapsular spread were not significant prognostic factors in this series. This is probably because most patients with bulky N2 or extracapsular spread at mediastinoscopy were considered to have unresectable disease and were therefore excluded from the study. As a consequence, the patients with bulky mediastinal nodes or extracapsular nodal disease included in our study represent a highly selected subgroup. Our results thus do not apply to the general population of patients with bulky $\mathrm{N} 2$ or extracapsular spread. Few reports in literature have dealt with the prognostic significance of skip metastases. Prenzel and colleagues ${ }^{20}$ reported a 5-year survival of $41 \%$ for patients with pN2 skip metastases, in contrast to $14 \%$ for patients with both $\mathrm{N} 1$ and N2 metastatic nodes. In our series, skip N2 metastases did not predict a better long-term survival.

The prognostic significance of the site of mediastinal nodes involved has already been investigated. A significantly worse prognosis has been reported for patients with metastases to subcarinal nodes. ${ }^{21,22}$ Goldstraw and associates ${ }^{6}$ found that metastases in subcarinal nodes had no adverse influence on survival. In our study, subcarinal node involvement was not associated with a worse prognosis. This may depend on the extensive preoperative staging of the mediastinum and routine MLND.

The recently published American College of Chest Physicians guidelines for patients with preoperatively identified $\mathrm{N} 2$ disease recommend chemoradiation as the standard therapy, with surgery considered after induction chemotherapy in the settings of a clinical trial. ${ }^{2}$ This study suggests that there are subsets of patients with preoperatively diagnosed N2 NSCLC who might benefit from a surgical approach. We are aware that our findings must be validated in further trials involving large series of patients before introducing them into clinical practice. Once validated, the prognostic algorithms developed in this study (see Figure 2) might constitute the base for future randomized trials investigating the role of surgery in treating patients with preoperatively demonstrated N2 NSCLC.

Regarding the optimal treatment options for patients with clinical N2 NSCLC, most authors have argued that these patients should not undergo surgery. ${ }^{7,9,10,23}$ Goldstraw and associates ${ }^{4}$ thoroughly summarized the conflicting results of long-term survival associated with surgery in patients with N2 NSCLC. Surgical series have reported 5-year survivals from $6 \%$ to $35 \% .{ }^{1,24}$ Such range reflects the inclusion of subsets of patients with $\mathrm{N} 2$ disease with different prognoses, and also differences in complete resection rates. We have confirmed that complete resection is a basic requirement for long-term survival and that surgery is justified only if a $\mathrm{R} 0$ resection can be achieved. CT scan does not provide definite landmarks for distinguishing between operable and inoperable preoperatively diagnosed N2 NSCLC. When only obvious cases were denied surgery, an incomplete resection rate as high as $40 \%$ was reported. ${ }^{25}$ The high complete resection rate that we observed $(79 \%)$ reflects our selective attitude in cases of positive mediastinoscopy and confirms that mediastinoscopy as a staging method is superior to CT scan for prevention of incomplete resections. The new generation of multiplanar multidetector CT scan will probably help in predicting a complete resection.

At present, the role of induction chemotherapy in N2 NSCLC remains debated. ${ }^{26-30}$ Our multivariate analysis indicates that among preoperative prognostic factors induction chemotherapy and the selection that occurs on the basis of therapeutic response is a significant predictor of better prognosis. In spite of the striking difference in survival between patients who underwent preoperative chemotherapy and those who underwent primary surgery, however, we cannot conclude that induction chemotherapy is effective in prolonging survival, because the percentage of patients who did not undergo surgery after preoperative chemotherapy was as high as $45.7 \%$. Since the inclusion of PET scan in the preoperative staging protocol coincided approximately with the use of induction chemotherapy, one might argue that the apparent survival advantage in the induction therapy group was due to better screening for distant metastases. The percentage of patients who did not undergo surgery exclusively on the basis of PET scan detection of distant metastases, however, was less than $2 \%$. This percentage is lower than others reported in the literature, possibly because of our extensive preoperative staging and because a single distant metastasis detected by PET scan was considered a contraindication to surgery only if confirmed by histologic or other diagnostic tests. Because of the very small number of patients excluded from the study as a result of the preoperative use of PET scan, we can conclude that induction 
chemotherapy acts as an effective tool for selecting patients for resection, helping to identify a subset of patients with improved prognosis.

The presence of residual N2 disease after induction therapy has been considered a contraindication to surgery. Bueno and associates ${ }^{31}$ reported 5-year survivals of $36 \%$ among 29 patients with downstaging to N0 and $9 \%$ among the 74 patients with residual N1 or N2 disease. Similar conclusions have been drawn by Voltolini and coworkers, ${ }^{32}$ Okada and associates, ${ }^{17}$ and Betticher and colleagues. ${ }^{33}$ In the SWOG trial $8805^{34}$ nodal downstaging was the only independent favorable prognostic factor identified in a multivariate model. Sawabata and colleagues ${ }^{35}$ investigated the influence on long-term survival of the number of mediastinal node levels with residual disease after induction chemotherapy. Five-year survival was significantly better in 18 patients $(54 \%)$ with residual disease at a single N2 level than in 25 patients $(11 \%)$ with multiple N2 level disease. In our series, the 5-year survival among 30 patients who had a complete response in the mediastinum was $69 \%$ (95\% confidence interval $50 \%-88 \%$ ), suggesting that nodal downstaging is associated with a better prognosis. Furthermore, we confirmed that the number of metastatic mediastinal nodes after induction chemotherapy is a significant prognostic factor. In our study, the response to induction chemotherapy was assessed by CT scan and PET scan, with remediastinoscopy never used. In a recent prospective study, De Leyn and colleagues ${ }^{36}$ demonstrated that remediastinoscopy was technically feasibly; however, the sensitivity and negative predictive value of remediastinoscopy were low because of fibrosis. PET scan proved to be more accurate than remediastinoscopy in the restaging of the mediastinum, with a very high positive predictive value. Because of the significant prognostic value of residual N2 disease at multiple levels after induction chemotherapy and the low accuracy of remediastinoscopy, we are now evaluating an alternative approach. When a preoperative PET scan shows a positive result in the mediastinum, an effort is made to obtain N2 demonstration by means of less invasive techniques than mediastinoscopy (such as transbronchial needle aspiration). Mediastinoscopy is used after induction chemotherapy to assess resectability to exclude residual tumor in multiple mediastinal node levels and to detect unsuspected N3 disease or paratracheal node metastases in left-sided NSCLC.

\section{CONCLUSIONS}

Because the prognosis after resection of patients with clinical N2 NSCLC is generally poor, there is a need for preoperative selection of subgroups of patients who may benefit from surgery. Although the design of this study does not allow inferences on the relative values of different staging protocols or treatment strategies, it does provide information on the prognoses of different subgroups of patients undergoing surgery for N2 NSCLC on the basis of significant preoperative prognostic factors. Although our study points out the usefulness of the significant postoperative factors for assessing patient prognosis, the value of these factors for planning adjuvant treatments remains to be evaluated. Patients with the favorable prognostic factors we have identified, whether preoperative or postoperative, have good long-term survivals (30\% and $48 \%$ at 5 years, respectively) and excellent local disease control $(73 \%$ and $89 \%$, respectively). Thus for these favorable subsets of patients with N2 NSCLC, surgery should still be included in the multimodality treatment until other therapeutic options have been demonstrated to guarantee better local disease control and long-term survival. Although our postoperative model proved to absorb all the preoperative prognostic factors, the preoperative model should be maintained as a useful tool for selecting among candidates for resection those patients who may have a better prognosis after surgery.

We thank Herbert Dal Corso for his help in preparing the manuscript.

\section{References}

1. Andre F, Grunenwald D, Pignon JP, Dujon A, Pujol JL, Brichon PY, et al. Survival of patients with resected N2-NSCLC: evidence for a subclassification and implications. J Clin Oncol. 2000;18:2981-9.

2. Robinson LA, Ruckdeschel JC, Wagner H Jr, Stevens CW. American College of Chest Physicians. Treatment of non-small cell lung cancer-stage IIIA: ACCP evidence-based clinical practice guidelines (2nd edition). Chest. 2007;132 (3 Suppl):243S-65S.

3. Albain KS, Swann RS, Rusch VR. Phase III study of concurrent chemotherapy and radiotherapy $(\mathrm{CT} / \mathrm{RT})$ vs $\mathrm{CT} / \mathrm{RT}$ followed by surgical resection for stage IIIA (pN2) non-small-cell lung cancer (NSCLC): outcomes update of North American Intergroup 0139 (RTOG 9309) [abstract]. Proc Am Soc Clin Oncol. 2005;23(suppl):7014. Abstract 7014

4. van Meerbeeck JP, Kramer GW, Van Schil PE, Legrand C, Smit EF, Schramel F, et al, European Organisation for Research and Treatment of Cancer-Lung Cancer Group. Randomized control trial of resection versus radiotherapy after induction chemotherapy in stage IIIA-N2 non-small-cell lung cancer. J Natl Cancer Inst. 2007;99:442-50.

5. Watanabe Y, Shimizu J, Oda M, Hayashi Y, Watanabe S, Tatsuzawa Y, et al. Aggressive surgical intervention in N2 non-small cell cancer of the lung. Ann Thorac Surg. 1991;51:253-61.

6. Goldstraw P, Mannam G, Kaplan D, Michail P. Surgical management of nonsmall-cell cancer with ipsilateral mediastinal node metastasis (N2 disease) J Thorac Cardiovasc Surg. 1994;107:19-28.

7. Ratto GB, Mereu C, Motta G. The prognostic significance of preoperative assessment of mediastinal lymph nodes in patients with lung cancer. Chest. 1988;93:807-13.

8. Shields TW. The significance of ipsilateral mediastinal lymph node metastasis (N2 disease) in non-small cell carcinoma of the lung. $J$ Thorac Cardiovasc Surg. 1990;99:48-53.

9. Pearson F, DeLarue N, Ilves R, Todd TR, Cooper JD. Significance of positive superior mediastinal nodes identified at mediastinoscopy in patients with resectable cancer of the lung. J Thorac Cardiovasc Surg. 1982;83:1-11.

10. Goldstraw $P$. The practice of cardiothoracic surgeons in the perioperative staging on non-small cell lung cancer. Thorax. 1992;47:1-3.

11. Pearson FG. Mediastinal adenopathy-the N2 lesion. In: DeLarue NC, Eschapasse H, eds. International trends in general thoracic surgery, vol. 1. Lung cancer. Philadelphia: WB Saunders; 1985. p. 104.

12. Backer CL, Shields TW, Lockhart CG, Vogelzang R, LoCicero J III. Selective preoperative evaluation for possible N2 disease in carcinoma of the lung. J Thorac Cardiovasc Surg. 1987;93:337-43.

13. Martini N, Flehinger BJ. The role of surgery in N2 lung cancer. Surg Clin North Am. 1987;67:1037-49.

14. Suzuki K, Nagai K, Yoshida J. The prognosis of surgically resected N2 non-small cell lung cancer: the importance of clinical N status. J Thorac Cardiovasc Surg. 1999; 118:145-53. 
15. Ruckdeshel JC. Combined modalities therapy of non-small cell lung cancer. Semin Oncol. 1997;24:429-39.

16. Vansteenkiste JF, De Leyn PR, Deneffe GJ, Stalpaert G, Nackaerts KL, Lerut TE, et al. Survival and prognostic factors in resected N2 non-small cell lung cancer: a study of 140 cases. Leuven Lung Cancer Group. Ann Thorac Surg. 1997;63: 1441-50.

17. Okada M, Tsubota N, Yoshimura M, Miyamoto Y, Matsuoka H. Induction therapy for non-small cell lung cancer with involved mediastinal nodes in multiple stations. Chest. 2000;118:123-8.

18. Ichinose Y, Kato H, Koike T, Tsuchiya R, Fujisawa T, Shimizu N, et al. Overall survival and local recurrence of 406 completely resected stage IIIa-N2 non-small cell lung cancer patients: questionnaire survey of the Japan Clinical Oncology Group to plan for clinical trials. Lung Cancer. 2001;34:29-36.

19. Keller SM, Adak S, Wagner H, Johnson DH. Mediastinal lymph node dissection improves survival in patients with stages II and IIIa non-small cell lung cancer. Eastern Cooperative Oncology Group. Ann Thorac Surg. 2000;70:358-66.

20. Prenzel KL, Baldus SE, Mönig SP, Tack D, Sinning JM, Gutschow CA, et al. Skip metastasis in nonsmall cell lung carcinoma: predictive markers and isolated tumor cells in N1 lymph nodes. Cancer. 2004;100:1909-17.

21. Naruke T, Suemasu K, Ishikawa K. Lymph node mapping and curability at various levels of metastasis in resected lung cancer. J Thorac Cardiovasc Surg. 1978;76:832-9.

22. Sawyer TE, Bonner JA, Gould PM. The impact of surgical adjuvant thoracic radiation therapy for patients with non-small cell lung carcinoma with ipsilateral mediastinal lymph node involvement. Cancer. 1997;80:1399-408.

23. Mountain CF. The biological operability of stage III non-small cell lung cancer. Ann Thorac Surg. 1985;40:60-4.

24. Vansteenkiste JF, De Leyn PR, Deneffe GJ, Lerut TE, Demedts MG. Clinical prognostic factors in surgically treated stage IIIA N2 non-small cell lung cancer: analysis of the literature. Lung Cancer. 1998;19:3-13.

25. Sioris T, Järvenpää R, Kuukasjärvi P, Helin H, Saarelainen S, Tarkka M. Comparison of computed tomography and systematic lymph node dissection in determining TNM and stage in non-small cell lung cancer. Eur J Cardiothorac Surg. 2003; 23:403-8.

26. Roth JA, Fossella F, Komaki R, Ryan MB, Putnam JB Jr, Lee JS, et al. A randomized trial comparing perioperative chemotherapy and surgery with surgery alone in resectable stage IIIA non-small cell lung cancer. J Natl Cancer Inst. 1994;86: 673-80.
27. Rosell R, Gómez-Codina J, Camps C, Maestre J, Padille J, Cantó A, et al. A randomized trial comparing preoperative chemotherapy plus surgery with surgery alone in patients with non-small cell lung cancer. N Engl J Med. 1994;330:153-8.

28. Depierre A, Milleron B, Moro-Sibilot D, Chevret S, Quoix E, Lebeau B, et al. Preoperative chemotherapy followed by surgery compared with primary surgery in resectable stage I (except T1N0), II, and IIIA non-small cell lung cancer. J Clin Oncol. 2002;20:247-53.

29. Nagai K, Tsuchiya R, Mori T, Tada H, Ichinose Y, Koike T, et al. A randomized trial comparing induction chemotherapy followed by surgery with surgery alone for patients with stage IIIA N2 non-small cell lung cancer (JCOG 9209). J Thorac Cardiovasc Surg. 2000;125:254-60.

30. Pass HI, Pogrebniak HW, Steinberg SM, Mulshine J, Minna J. Randomized trial of neoadjuvant therapy for lung cancer: interim analysis. Ann Thorac Surg. 1992;53: 992-8.

31. Bueno R, Richards WG, Swanson SJ, Jaklitsch MT, Lukanich JM, Mentzer SJ, et al. Nodal stage after neoadjuvant therapy for stage IIIA lung cancer determines patient survival. Ann Thorac Surg. 2000;70:1826-31.

32. Voltolini L, Luzzi L, Ghiribelli C, Paladini P, Di Bisceglie M, Gotti G. Results of induction chemotherapy followed by surgical resection in patients with stage IIIA (N2) non-small cell lung cancer: the importance of the nodal down-staging after chemotherapy. Eur J Cardiothorac Surg. 2001;20:1106-12.

33. Betticher DC, Hsu Schmitz SF, Tötsch M, Hansen E, Joss C, von Briel C, et al. Mediastinal lymph node clearance after docetaxel-cisplatin neoadjuvant chemotherapy is prognostic of survival in patients with stage IIIA pN2 non-small-cell lung cancer: a multicenter phase II trial. J Clin Oncol. 2003;21:1752-9.

34. Albain KS, Rusch VW, Crowley JJ, Rice TW, Turrisi AT 3rd, Weick JK, et al. Concurrent cisplatin/etoposide plus chest radiotherapy followed by surgery for stages IIIA (N2) and IIIB non-small-cell lung cancer: mature results of Southwest Oncology Group phase II study 8805. J Clin Oncol. 1995;13:1880-92.

35. Sawabata N, Keller SM, Matsumura A, Kawashima O, Hirono T, Osaka Y, et al. The impact of residual multi-level N2 disease after induction therapy for nonsmall cell lung cancer. Lung Cancer. 2003;42:69-77.

36. De Leyn P, Stroobants S, De Wever W, et al. Prospective comparative study of integrated positron emission tomography-computed tomography scan compared with remediastinoscopy in the assessment of residual mediastinal lymph node disease after induction chemotherapy for mediastinoscopy-proven stage IIIA-N2 non-small-cell lung cancer: a Leuven Lung Cancer Group Study. J Clin Oncol. 2006;24:3333-9. 